\title{
Somogy megye „féregfaunájának” adatai a XX. század végén
}

\author{
MÉSZÁros FERENC
}

MÉSZÁROS F: Data of the worm fauna of Somogy county at the end of the 20th century

Abstract: The subsequent list contains the known Platyhelminthes, Nematoda and earthworm species collected in Somogy county.

\section{Bevezetés}

Somogy megye féregfaunájáról a jelenleg ismert és fellelhetô adatok alapján nagyon hiányosak az ismereteink. A szórványos adatok, nagyobb taxonómiairevíziós munkák részeként megjelenő fajjegyzékek, előfordulási adatok a vélhetően gazdag fauna töredékét reprezentálják. A rendelkezésünkre álló adatokból tehát a faunáról szinte semmiféle értékelés nem adható. A szerény adattömeg a kutatások hiányára, illetóleg azok szükségességére hívja fel a figyelmet.

A következôkben „féreg” törzsenként (ahol az indokolt osztályonként) közöljük a megye területérổl ismert fajokat a lelóhelyekkel. Az élốsködőknél a gazdaállat nevét is megadjuk.

\section{Somogyból ismert fajok jegyzéke}

\section{LAPOSFÉrgek (Platyhelminthes)}

\section{Galandférgek (Cestoda)}

Myotolepis grisea (Beneden, 1873);

Somogyjád.

Gazda: Myotis myotis.

Hymenolepis diminuta (Rudolphi, 1819);

Somogyszob, (Kaszó-puszta).

Gazda: Apodemus flavicollis.

Skrjabinotaenia lobata (Baer, 1925);

Somogyszob, (Kaszó-puszta).

Gazda: Apodemus flavicollis.

Cladotaenia globifera (Batsch, 1786);

Somogyszob, (Kaszó-puszta).

Gazda: Apodemus flavicollis.

Taenia taeniaeformis Batsch, 1786(metacestoda); Fonó.

Gazda: Mus musculus.
Andrya rhopalocephala (Riehm, 1881); Somogysimonyi.

Gazda: Lepus europaeus.

\section{Közvetett fejlődésư mételyek (Trematoda)}

Dicrocoelium dendriticum Stiles et Hassal, 1896; Hollád.

Gazda: Lepus europaeus.

\section{Fonálférgek (Nematoda)}

„Szabadon" élô fonálférgek

Mesotheristus crassissimus (Ditlevsen, 1911);

Balatonszárszó, Balatonmária-fürdó.

Mesotheristus dubius (Bütschli, 1873); Balatonszárszó, Balatonmária-fürdô, Balatonberény, Balatonfenyves. fok.

Eumonhystera andrassyi (Bíró, 1969); Sió-

Eumonhystera dispar (Bastian, 1865); Bala- 
tonszárszó, Balatonfenyves, Balatonberény.

Eumonhystera vulgaris (de Man, 1880); Balatonmária-fürdó, Balatonfenyves, Balatonberény.

Paraphanolaimus ansitsi (Daday, 1905); Balatonföldvár.

Paraphanolaimus behningi Micoletzky, 1923; Balatonmária-fürdő.

Anaplectus grandepapillatus (Ditlevsen, 1928); Balatonmária-fürdő, Balatonfenyves.

Anaplectus granulosus (Bastian, 1865); Balatonszárszó, Balatonfenyves, Balatonberény.

Plectus aquatilis Andrássy, 1985; Balatonszárszó, Balatonfenyves, Balatonberény.

Plectus cirratus Bastian, 1865; Balatonfenyves.

Plectus parietinus Bastian, 1865; Balatonmária-fürdő, Balatonfenyves.

Plectus parvus Bastian, 1865; Balatonmáriafürdô, Balatonfenyves.

Plectus rhizophilus de Man, 1880; Balatonberény.

Plectus tenuis Bastian 1865; Balatonszárszó, Balatonmária-fürdô, Balatonberény.

Tylocephalus auriculatus (Bütschli, 1873); Balatonmária-fürdő.

\section{Siófok.}

Prodesmodora circulata (Micoletzky, 1913) ;

Achromadora ruricola (de Man, 1880);

Balatonfenyves, Balatonberény.

Achromadora terricola (de Man, 1880);

Balatonberény.

Chromadorina bioculata (Schultze, 1857);

Balatonmária-fürdó, Balatonfenyves, Balatonberény.

Punctodora dudichi Andrássy, 1966; Balatonmária-fürdő, Balatonfenyves, Balatonberény.

Metateratocephalus crassidens (de Man, 1880) ; Balatonszárszó, Balatonmária-fürdó.

Eucephalobus mucronatus (Kozlowska et Waszilewska, 1963) ; Balatonberény.

Eucephalobus oxyuroides (de Man, 1876) ; Balatonmária-fürdô.

Acrobeles cylindricus Ivanova, 1968; Fonyód.

Chiloplacus symmetricus (Thorne, 1925); Balatonmária-fürdô.

Seleborca timmi (Chaturvedi et Khera, 1979), Siófok.

Panagrolaimus rigidus (Schneider, 1866); Siófok, Balatonmária-fürdô.

Myolaimus heterurus Cobb, 1920; Balatonberény.

Myolaimus stammeri Hirschmann, 1952; Balatonberény.
Curviditis dimorpha (Sudhaus, 1976);

Balatonberény.

Mesorhabditis spiculigera (Steiner, 1936); Balatonmária-fürdő.

Bunonema hessi Steiner, 1914; Balatonmária-fürdő.

Fictor fictor (Bastian, 1865); Balatonfenyves.

Filenchus vulgaris (Brzeski, 1963); Balatonmária-fürdő.

Psilenchus hilarulus (de Man, 1921), Szántód, Balatonszárszó.

Merlinius nanus (Allen, 1955); Szántód.

Hirschmanniella gracilis (de Man, 1880); Balatonszárszó.

Helicotylenchus multicinctus (Cobb, 1893); Balatonfenyves.

Macroposthonia ornata (Raski, 1958); Szántód.

Macroposthonia spherocephala (Taylor, 1936); Szántód.

Macroposthonia xenoplax (Raski, 1952); Balatonmária-fürdô, Balatonfenyves.

Seriespinula hungarica Andrássy, 1962; Balatonmária-fürdő.

Hemicycliophora aquatica (Micoletzky, 1913); Balatonszárszó, Balatonmária-fürdō.

Bastiania gracilis de Man, 1876; Balatonmária-fürdô.

Odontolaimus chlorurus de Man, 1880; Balatonszárszó, Fonyód, Balatonfenyves.

Alaimus arcuatus Thorne, 1939; Balatonmária-fürdô.

Alaimus primitivus de Man, 1880; Balatonmária-fürdő, Balatonberény.

Tripyla filicaudata de Man, 1880; Balatonfenyves.

Tripyla glomerans Bastian, 1865; Balatonszárszó, Balatonberény.

Tripyla papillata Bastian, 1865; Balatonfenyves.

Trischistoma monohystera (de Man, 1880); Balatonmária-fürdő.

Tobrilus helveticus (Hoffmanner, 1915); Balatonfenyves.

Tobrilus allophysis (Steiner, 1919); Balatonfenyves, Balatonberény.

Tobrilus gracilis Bastian, 1865; Balatonberény.

Neotobrilus longus (Leidy, 1851); Balatonmária-fürdő, Balatonfenyves, Balatonberény.

Prismatolaimus dolichurus de Man, 1880; Balatonberény.

Prismatolaimus intermedius (Bütschli, 1873); Balatonszárszó, Balatonfenyves. 
Ironus tenuicaudatus de Man, 1876; Balatonszárszó, Balatonfenyves.

Monochus aquaticus Coetzee, 1968; Balatonberény.

Monochus niddensis Skwarra, 1921; Balatonszárszó.

Monochus pulcher Andrássy, 1993; Balatonszárszó, Balatonfenyves.

Monochus truncatus Bastian, 1865; Balatonmária-fürdő, Balatonfenyves, Balatonberény.

Prionchulus muscorum (Dujardin, 1845); Balatonszárszó, Balatonfenyves, Balatonberény.

Mylonchulus brachyuris (Bütschli, 1873);

Balatonmária-fürdő, Balatonfenyves.

Mynolonchulus lacustris (Cobb, 1915); Balatonszárszó, Balatonmária-fürdő.

Nygolaimus brachyuris (de Man, 1880); Balatonszemes.

Clavicaudoides clavicaudatus (Altherr, 1953); Balatonmária-fürdő.

Thornia propinqua (Paesler, 1940); Balatonfenyves.

Dorylaimus afghanicus Andrássy, 1960; Balatonberény.

Dorylaimus helveticus Steiner 1919; Balatonmária-fürdő.

Dorylaimus stagnalis Dujardin, 1845; Balatonszárszó, Balatonfenyves, Balatonberény.

Ischiodorylaimus cognatus Andrássy, 1983; Balatonberény.

Crocodorylaimus flavomaculatus (Linstow, 1876); Balatonszárszó.

Mesodorylaimus bastiani (Bütschli, 1873); Balatonszárszó, Balatonfenyves, Balatonberény.

Mesodorylaimus parasubtilis (Meyl, 1957);

Balatonmária-fürdô, Balatonfenyves.

Mesodorylaimus subtilis (Thorne et Swanger, 1936); Balatonmária-fürdô.

Baladorylaimus balatonicus Andrássy, 2000; Balatonszárszó.

Aporcelaimellus obtusicaudatus (Bastian, 1865); Siófok, Balatonszárszó, Balatonmáriafürdő, Balatonfenyves, Balatonberény.

Eudorylaimus carteri (Bastian, 1865);

Balatonberény.

Ecumenicus monohystera (de Man, 1880); Ba-

latonszárszó, Balatonmária-fürdô

Labronemella labiata (Andrássy, 1985);

Balatonfenyves.

Pungentus angulosus Jairajpuri and Baqri, 1966; Szántód.

Pungentus engadinensis (Altherr, 1950); Szántód.

Oxydirus oxycephaloides (de Man, 1921);
Balatonmária-fürdő, Balatonfenyves.

Paractinolaimus macrolaimus (de Man, 1884); Balatonszárszó, Balatonmária-fürdő, Balatonberény.

Tylencholaimus minimus de Man, 1876;

Balatonmária-fürdő, Balatonfenyves.

Calolaimus ditlevseni (Micoletzky, 1922);

Balatonszárszó.

Diphtherophora perplexans (Cobb, 1913);

Balatonmária-fürdő.

\section{Élósködố fonálférgek}

Litomosa desportesi Bain, 1967; Somogyjád. Gazda: Myotis myotis.

Heligmosomum mixtum Schulz, 1954; Iharos-

berény.

Gazda: Clethrionomys glareolus.

Heligmosomoides glareoli, Baylis, 1928;

Iharosberény, Somogyszob.

Gazda: Clethrionomys glareolus.

Trichostrongylus retortaeformis (Zeder, 1800);

Iharosberény, Somogysimonyi, Hollád.

Gazda: Clethrionomys glareolus, Lepus europaeus.

Angiostrongylus (P.) dujardini Drozdz et

Doby, 1970; Iharosberény.

Gazda: Clethrionomys glareolus.

Trichocephalus muris Schrank, 1788; Fonó.

Gazda: Mus musculus.

Trichocephalus sylvilagi (Tiner, 1950);

Somogysimonyi.

Gazda: Lepus europeaus

Aspiculuris tetraptera (Nitzsch, 1821); Fonó.

Gazda: Mus musculus.

Passalurus ambiguus (Rudolphi, 1819);

Somogysimonyi

Gazda: Lepus europaeus.

\section{GYứRÜSFÉrGEK (ANNELIDA)}

Lumbricus rubellus, Hoffmeister, 1843; Balatonboglár, Bélatelep, Balatonszabadi, Balatonberény, Balatonmária-fürdó, Simonfa, Zselicszentpál, Ropolypuszta, Nagybajom, Szőkedencs, Hollád, Ôrtilos, Cserfekvés, Heresznye és Vízvár között, Drávatamási, Bőszénfa, Csurgónagymarton, Somogycsicsó, Porrogszentpál, Szentbalázs, Barcs.

Lumbricus terrestris Linnaeus, 1758, Böhönye, OOrtilos, Somogyújvár.

Lumbricus polyphemus (Fitzinger, 1833); Ropolypuszta, Hencse, Ốrtilos, Bőszénfa, Somogybükkösd, Somogycsicsó.

Eisena foetida (Savigny, 1826); Balatonboglár, Balatonberény, Bélatelep, Órtilos. 
Eisenia spelaea (Rosa, 1091); Somogybükkösd, Csurgónagymarton.

Dendrodrilus rubidus rubidus (Savigny, 1826); Barcs, Balatonberény.

Dendrodrilus rubidus subrubicundus (Eisen, 1874); Barcs.

Dendrodilus rubidus tenuis (Eisen, 1874); Balatonmária-fürdō, Balatonberény, Barcs.

Dendrobaena octaedra (Savigny, 1826); Balatonboglár, Fonyód, Bélatelep, Cserfekvésmajor, Ropolypuszta, Barcs, Bószénfa, Balatonmária-fürdô, Ôrtilos.

Eiseniella tetraedra tetraedra (Savigny, 1826); Szántód, Balatonzamárdi, Balatonszéplak, Siófok, Balatonszabadi, Balatonboglár, Fonyód, Bélatelep, Balatonfenyves, Balatonmária-fürdő, Balatonberény, Barcs.

Eiseniella tetraedra. hercynia (Savigny, 1826); Balatonzamárdi, Balatonszéplak.

Eiseniella tetraedra intermedia (Cernosvitov, 1934); Porrogszentpál.

Eiseniella balatonica (Pop, 1943), Balatonboglár, Balatonmária-fürdő, Barcs.

Octodriloides karawankensis (Zicsi, 1969); Böszénfa.

Octodrilus transpadanus (Rosa, 1884); Balatonmária-fürdő, Balatonberény, Balatonzamárdi, Balatonfenyves, Nagybajom, Fonyódliget, Toponár, Szôkedencs.

Octodrilus pseudotranspadanus (Zicsi, 1971); Csurgónagymarton, Somogybükkösd, Porrogszentpál.

Octolasium lacteum (Örley, 1885); Balatonboglár, Fonyód, Bélatelep, Balatonberény, Balatonmária-fürdő, Somogybükkösd, Dennapuszta, Szentpál, Balatonfenyves, Simonfa, Ropolypuszta, Nagybajom és Böhönye között, Szôkedencs, Örtilos, Heresznye és Vízvár között, Drávatamási, Kisvadár, Szentbalázs.

Allolobophora rosea rosea (Savigny, 1826); Balatonszéplak, Balatonszabadi, Balatonboglár, Fonyód, Bélatelep, Balatonfenyves, Látrány, Simonfa, Szőkedencs, Zselicszentpál, Hollád, Örtilos, Drávatamási, Heresznye és Vízvár között, Balatonmária-fürdő, Böszénfa, Ropolypuszta, Dennapuszta, Somogybükkösd, Csurgónagymarton, Somogycsicsó, Toponár.

Allolobophora chlorotica (Savigny, 1826); Balatonmária-fürdő.

Allolobophora handlirschi Rosa, 1897; Böszénfa.
Allolobophora leoni (Michaelsen, 1891); Balatonzamárdi, Balatonföldvár, Balatonboglár, Heresznye és Vízvár között, Simonfa, Ropolypuszta, Żselicszentpál, Bôszénfa, Dennapuszta, Szentbalázs.

Allolobophora caliginosa (Savigny, 1826); Balatonszabadi, Balatonszemes, Balatonboglár, Bélatelep, Balatonfenyves, Látrány, Simonfa, Zselicszentpál, Hencse, Örtilos, Bószénfa, Dennapuszta, Ropolypuszta, Somogybükkösd, Csurgószentmárton, Toponár.

Allolobophora jassyensis (Michaelsen, 1891); Balatonzamárdi, Balatonboglár.

Allolobophora georgii Michaelsen, 1890; Ropolyapuszta.

Allolobophora sineporis (Omodeo, 1952); Ropolypuszta.

Allolobophora dubiosa (Örley, 1881); Balatonszéplak, Balatonboglár.

Proctodrilus tuberculatus (Cernosvitov, 1935); Simonfa, Drávatamási, Heresznye és Vízvár között, Bőszénfa, Ropolypuszta, Dennapuszta, Csurgónagymarton, Somogycsicsó, Zselicszentpál.

Fitzingeria platyura depressa (Rosa, 1893); Bőszénfa, Ropolypuszta, Dennapuszta, Balatonboglár.

Az alábbi 19 televényféreg faj lelôhelye Balatonszárszó, Balatonberény.

Achaeta pannonica Graefe, 1989;

Buchholzia appendiculata (Buchholz, 1862)

Cognettia glandulosa (Michaelsen, 1888)

Cernosvitoviella minor Dózsa-Farkas, 1990

Enclytraeus bucholzi Vejdovsky, 1879

Enchytraeus bulbosus Nielsen et Christensen, 1963

Enchytraeus christenseni Dózsa-Farkas, 1992

Enchytraeus lacteus Nielsen, et Christensen, 1961

Fridericia bulbosa (Rosa, 1887)

Fridericia galba (Hoffmeister, 1843)

Fridericia paroniana Issel, 1904

Fridericia sp. 1959

Hemifridericia parva Nielsen et Christensen,

Henlea heleotropha (Steph., 1922)

Henlea nasuta (Eisen, 1878)

Henlea perpusilla Friend, 1911

Henlea ventriculosa (d'Udekem, 1954)

Marionina argentea (Michaelsen, 1889)

Marionina riparia Bretschser, 1899 


\title{
Irodalom
}

ANDRÁSSY, I. 2001: A Balaton somogyi partvidékéról kimutatott fonálféregek (Nematoda). Kézirat, 5 old.

DÓzSA FARKAS, K. 1998: The enchytraeid fauna (Annelida, Oligochaeta) of accumulated debris along the shore of Lake Balaton, and seasonal dynamics of the Species - Opusc. Zool. 31: 33-42.

KrISKA, T. 1993: Parasitic helminths of house mouse (Mus musculus Linnaeus, 1758) in Hungary - Miscnea zool. Hung. 8: 13-23.

MÉSZÁROS, F, 1971: Vizsgálatok a hazai denevérek élősködő fonálférgein (Nematoda) - Állatt. Közl. LVII: 78-86.

MÉsź́ros, F. 1978: Parasitic Nematodes of Clethrionomys glareolus (Rodentia) in Hungary Parasit. Hung. 11: 87-100.

MURAI, É. 1972: A magyarországi Apodomus-fajokban élősködő galandférgekröl (Cestoda) Parasit. Hung. 5: 47-82.

MURAI, É. 1976: Cestodes of bats in Hungary - Parasit. Hung. 9: 41-62.

SugÁr, L. - MurAI, É. - MÉSZÁros, F., 1978: Über die Endoparasiten der wildlebenden Leporidae Ungarns - Parasit. Hung. 11: 63-85.

ZiCSI, A. 1968: Ein zusammenfassendes Verbreitungsbild der Regenwürmer auf Grund der Boden - und Vegetationsverhältnisse Ungarns - Opusc. Zool. 8(1): 99-164.

ZıCsı, A. 1991: Über die Regenwürmer Ungarns (Oligochaeta: Lumbricidae) mit Bestimmungstabellen der Arten - Opusc. Zool. 24: 167-191.

\section{Data of the worm fauna of Somogy county at the end of the $20^{\text {th }}$ century}

\author{
FERENC MÉSZÁROS
}

The occurrence references of 7 Platyhelminthes, 98 Nematoda and 47 earthworms have been compiled from collection and literature data taken from Somogy county. The known sporadic data are unsuitable for drawing any conclusions that would meet a $2 \mathrm{I}^{\text {"t }}$ century requirement.

Author's address:

Dr. Ferenc MÉszáros

Hungarian Natural History Museum

H-1088 Budapest

Baross u. 13.

HUNGARY 